\title{
Improving the accuracy of the height-diameter equation using the classified factors method
}

\author{
Yi-Fu Wang $\cdot$ Tian-Xiang Yue $\cdot$ Zheng-Ping Du • \\ Ming-Wei Zhao
}

Received: 8 October 2014/ Accepted: 7 February 2015/Published online: 1 March 2015

(C) Springer-Verlag Berlin Heidelberg 2015

\begin{abstract}
The height-diameter relationship model is crucial in the estimation of forest stand volume, biomass and carbon storage, etc. To improve prediction accuracy, the classified factors method for height-diameter relationship modeling was developed based on the classified height method. The data set contained 959 tree samples obtained from 28 plots measured by topographic factors (aspect, slope position and altitude). The Chapman-Richards equation was used to build models. Classification methods have improved fitting performance and prediction accuracy compared to the classical method. The classified height method has the best fitting performance because it has the highest determination coefficient $\left(R^{2}=0.927\right)$ and the lowest root mean square error $(\mathrm{RMSE}=1.548)$, whereas the classified factors method has the highest prediction accuracy because it has the lowest mean absolute error $(\mathrm{MAE}=1.137)$ and mean relative error $(\mathrm{MRE}=0.109)$.
\end{abstract}

Keywords Height-diameter model - Topographic factor . Picea crassifolia $\cdot$ Height classification · Site · Chapman-Richards equation

Y.-F. Wang · T.-X. Yue $(\bowtie) \cdot$ Z.-P. Du · M.-W. Zhao

State Key Laboratory of Resources and Environment Information System, Institute of Geographical Sciences and Natural Resources Research, Chinese Academy of Sciences, 100101 Beijing, PR China

e-mail: yue@lreis.ac.cn

Y.-F. Wang

e-mail: wangyf@1reis.ac.cn

Y.-F. Wang · M.-W. Zhao

University of Chinese Academy of Sciences, Beijing, PR China

\section{Introduction}

Diameter at breast height (DBH) and tree height are two significant factors in calculating and estimating stand volume, biomass and carbon storage. DBH is measured for all tree samples in most forest surveys on account of the fixed relationship between DBH and tree growth as well as ease of measurement. However, tree height is generally only measured for a subsample due to the difficulty of obtaining accurate measurements. Tree heights of trees measured only in diameter have to be estimated through height-diameter relationship models. Therefore, building heightdiameter relationship models is an essential part of forest growth and yield estimation.

In previous studies, researchers have tried to find a more biologically feasible model to explain the relationship between height and DBH. Many linear and nonlinear heightdiameter models have been built and applied (Curtis 1967; Wykoff et al. 1982; Larsen and Hann 1987; Wang and Hann 1988; Huang et al. 1992; Zhang 1997; Fang and Bailey 1998; Fekedulengn et al. 1999; Jayaraman and Zakrzewski 2001; Peng et al. 2001; Sharma and Zhang 2004; Sharma and Parton 2007; Robinson and Wykoff 2004; Newton and Amponsah 2007; Lei et al. 2009; Esteban et al. 2014), including the Chapman-Richards model (Richards 1959; Chapman 1961), the Schnute model (Schnute 1981), the Weibull model (Yang et al. 1978), the Logistic model (Ratkowsky and Reedy 1986), the Korf model (Stage 1963; Zeide 1989; Mehtätalo 2004) and the Gompertz model, among others. In these models, the parameters are described as maximum height and rate, etc. Fang and Bailey (1998) built a Richard equation to explain the relationship between Height and DBH, providing a useful and economical alternative to attempting height measurements during inventories of forests. Huang et al. 
(2000) compared 27 candidate model forms, and selected the Logistic equation for height-diameter modeling for white spruce in boreal forests. Zhang (1997) applied 6 model forms to build height-diameter relationship models for the same data set. They found that six growth functions performed well for small trees. For large trees, however, these six growth functions either overestimated or underestimated tree heights. The Schnute, Weibull, and Richards functions proved superior in prediction performance as compared to the other models.

Mechanism models have been applied widely because of their biological suitability. However, it is hard to improve fit precision and predictive ability for mechanism models, in which $\mathrm{DBH}$ is the only variable predictor. Yet, site, density, forest type, wind, et al. are also key factors in the growth of tree height, in addition to DBH (Calama and Montero 2004; Temesgen et al. 2008, 2014). Sharma and Zhang (2004) improved the classical Richard function through introducing basal area, density and site index into models. The Chapman-Richards growth function with asymptote, rate and shape parameters explained in terms of basal area, stand density and site index, respectively, resulted in the best fit for the jack pine and black spruce. All the parameter estimates can be biologically interpreted and are consistent with growth theory. In a subsequent study (Sharma and Parton 2007), a fixed-effects modeling approach was developed and a random parameter was included in the previous model to explain the variance of height-diameter relationships among plots.

In contrast to fixed-effects modeling, some researchers developed discrete models to express the variance of height-diameter relationships among different geographical or ecological regions (Fulton 1999; Huang et al. 2000; Zhang et al. 2002; Li and Fa 2011; Li and Zhao 2013). They thought that maximum height in different regions was variable, but that the rate of height growth was not. Fulton (1999) developed a Richard model with three asymptote parameters in terms of three maximum heights performed in three regions. However, $\mathrm{Li}$ and $\mathrm{Fa}$ (2011) insisted that height-diameter models for different sites were difficult to build, taking into account that it is impossible to completely survey the site of a specific tree species in any country in the world. For their study, the classified height method was developed and the site was divided into several classes in terms of a series of curves generated using the classified height method. This model could estimate tree heights in large regions, in cases where surveying the site of the tree species was not possible.

Picea crassifolia forest, a specific forest type in the northeast of the Qinghai-Tibet Plateau, plays an important role in soil and water conservation and ecological recovery. $P$. crassifolia is sensitive to changes in topographic factors (e.g. slope, slope position, aspect and altitude) and an appropriate height-diameter model for $P$. crassifolia taking into consideration topographic factors is essential in surveying forests and estimating growth and yield. The objectives of this study were to build a height-diameter relationship discrete model for $P$. crassifolia using the classified factors method, and to improve the prediction accuracy of $P$. crassifolia tree height estimation.

\section{Materials and methods}

Data

Data used in this study were obtained from 28 sample plots established in Qilian Mountain in the Gansu province in China in 2013. Twenty-six of these sample plots contain only P. crassifolia; two contain P. crassifolia and Sabina przewalskii, but only $P$. crassifolia is taken into consideration in this study. The data set contains plot level and tree level information (Table 1). Tree level information includes $\mathrm{DBH}$ [diameter in breast height $(1.3 \mathrm{~m})$ ] and total height. Plot level information includes position of plot, altitude, aspect, slope position, et al. The data set contains 959 tree samples, which were divided into a fit data set with 574 samples and a validation data set with 385 samples (Fig. 1).

The classified height method

The Chapman-Richard equation Eq. (1) was used to express the relationship between height and diameter.

$y=1.3+a \cdot\left(1-\mathrm{e}^{-b \cdot x}\right)^{c}$

The algorithm of the classified height method follows:

1. To calculate the diameter class for each sample tree $D_{i j}=\operatorname{int}\left(d_{i j} / 2+0.5\right) \times 2$

where, $D_{i j}$ is diameter class of $j$ th sample tree within the $i$ th plot. $D_{i j} \in\left\{6,8, \ldots, D_{\max }\right\} . D_{\max }$ is the largest diameter class. $d_{i j}$ is diameter of $j$ th sample tree within the $i$ th plot.

2. To divide tree samples within each diameter into $m$ subsamples

To calculate $H_{\max }^{D}, H_{\min }^{D}$ and $H_{\text {class }}^{D}$ for each diameter class.

$H_{\max }^{D}=\max \left\{h_{i j} \mid D_{i j}=D\right\}$

$H_{\text {min }}^{D}=\min \left\{h_{i j} \mid D_{i j}=D\right\}$

$H_{\text {class }}^{D}=\left(H_{\max }^{D}-H_{\min }^{D}\right) / m$

where, $H_{\max }^{D}, H_{\min }^{D}$ and $H_{\text {class }}^{D}$ are the maximum tree height, the minimum tree height and class interval for diameter class $D$, respectively. $D \in\left\{6,8, \ldots, D_{\max }\right\}$. $h_{i j}$ is tree height of $j$ th sample tree within the $i$ th plot. $m$ is the number of height classes.

To calculate $l_{i j}$ 
Table 1 Description of plot level and tree level information of 28 plots

\begin{tabular}{|c|c|c|c|c|c|c|c|c|}
\hline \multirow[t]{2}{*}{ Plot } & \multicolumn{3}{|c|}{ Number of trees } & \multirow[t]{2}{*}{ Aspect } & \multirow[t]{2}{*}{ Altitude (m) } & \multirow[t]{2}{*}{ Slope position } & \multirow[t]{2}{*}{ Average DBH $(\mathrm{cm})$} & \multirow[t]{2}{*}{ Average height (m) } \\
\hline & Total & Fit data & Validation data & & & & & \\
\hline 1 & 59 & 35 & 24 & WN & 3141 & Middle slope & 9.94 & 3.39 \\
\hline 2 & 17 & 10 & 7 & W & 3089 & Bottom slope & 21.67 & 11.09 \\
\hline 3 & 18 & 11 & 7 & WS & 3117 & Middle slope & 10.57 & 5.43 \\
\hline 4 & 106 & 63 & 43 & $\mathrm{EN}$ & 3045 & Bottom slope & 9.9 & 7.08 \\
\hline 5 & 21 & 13 & 8 & $\mathrm{~N}$ & 3078 & Bottom slope & 20.06 & 9.85 \\
\hline 6 & 64 & 38 & 26 & W & 3123 & Top slope & 13.24 & 7.96 \\
\hline 7 & 44 & 26 & 18 & WN & 3157 & Bottom slope & 12.58 & 7.74 \\
\hline 8 & 21 & 13 & 8 & $\mathrm{EN}$ & 3203 & Middle slope & 13.76 & 7.13 \\
\hline 9 & 16 & 10 & 6 & EN & 3225 & Bottom slope & 21.25 & 10.71 \\
\hline 10 & 16 & 10 & 6 & WN & 3205 & Bottom slope & 25.28 & 11.71 \\
\hline 11 & 6 & 4 & 2 & ES & 3029 & Bottom slope & 39.07 & 21.08 \\
\hline 12 & 49 & 29 & 20 & WN & 3041 & Bottom slope & 14.23 & 9.38 \\
\hline 13 & 16 & 10 & 6 & $\mathrm{E}$ & 3099 & Bottom slope & 23.52 & 14.04 \\
\hline 14 & 34 & 20 & 14 & $\mathrm{~N}$ & 3038 & Bottom slope & 15.64 & 11.01 \\
\hline 15 & 27 & 16 & 11 & EN & 2984 & Top slope & 19.81 & 13.02 \\
\hline 16 & 40 & 24 & 16 & $\mathrm{~N}$ & 2991 & Middle slope & 16.07 & 12.81 \\
\hline 17 & 39 & 23 & 16 & WN & 3032 & Top slope & 14.97 & 10.35 \\
\hline 18 & 46 & 28 & 18 & EN & 2926 & Middle slope & 13.67 & 10.65 \\
\hline 19 & 108 & 64 & 44 & EN & 2828 & Bottom slope & 10.03 & 8.95 \\
\hline 20 & 19 & 11 & 8 & $\mathrm{~N}$ & 2808 & Bottom slope & 18.82 & 13.52 \\
\hline 21 & 24 & 14 & 10 & $\mathrm{~N}$ & 2692 & Bottom slope & 15.56 & 10.82 \\
\hline 22 & 37 & 22 & 15 & $\mathrm{~N}$ & 2724 & Bottom slope & 10.43 & 7.66 \\
\hline 23 & 26 & 16 & 10 & $\mathrm{~N}$ & 2737 & Middle slope & 17.6 & 11.42 \\
\hline 24 & 26 & 16 & 10 & $\mathrm{~N}$ & 2881 & Middle slope & 16.91 & 12.43 \\
\hline 25 & 34 & 20 & 14 & EN & 2931 & Middle slope & 14.6 & 10.44 \\
\hline 26 & 11 & 7 & 4 & WN & 2925 & Bottom slope & 30.23 & 20.32 \\
\hline 27 & 29 & 17 & 12 & WN & 2905 & Middle slope & 20.4 & 14.62 \\
\hline 28 & 6 & 4 & 2 & WS & 2909 & Bottom slope & 32.5 & 16.44 \\
\hline
\end{tabular}

$N$ north slope, $S$ south slope, $E$ east slope, $W$ west slope, $N E$ northeast slope, $N W$ northwest slope, $S E$ southeast slope, $S W$ southwest slope

$$
l_{i j}=\left\{\begin{array}{lll}
k, & \text { if } H_{\min }^{D}+(k-1) H_{\text {class }}^{D} \leq h_{i j} \leq H_{\text {min }}^{D}+k H_{\text {class }}^{D}, \quad 5 . & \text { To fit Eq. (2) and estimate } a_{1}, a_{2}, \ldots, a_{\mathrm{m}}, b \text { and } c \\
& k=1,2, \cdots, m-1 & h_{i j}=1.3+\left(\text { Design }_{1 \times m}\right)_{i j} \cdot a_{m \times 1} \cdot\left(1-\mathrm{e}^{-b \cdot d_{i j}}\right)^{c}+\varepsilon_{i j} \\
m, & \text { if } H_{\min }^{D}+(k-1) H_{\text {class }}^{D} \leq h_{i j} \leq H_{\max }^{D}, k=m
\end{array}\right.
$$

where, $l_{i j}$ is tree height class of $j$ th sample tree within the $i$ th plot.

3. To initialize $t_{1}$ and $t_{2}$

$t_{1}=0$

$t_{2}=0$

where, $t_{1}$ and $t_{2}$ are iterations of inner and outer iteration, respectively.

4. To build design matrix $\left(\text { Design }_{1 \times m}\right)_{i j}$ of tree height classification

$\left(\operatorname{Design}_{k}\right)_{i j}=\left\{\begin{array}{ll}1 & k=l_{i j} \\ 0 & k \neq l_{i j}\end{array}, \quad k=1,2, \cdots m\right.$

where, $\left(\operatorname{Design}_{k}\right)_{i j}$ is the $k$ th element of design vector for $j$ th sample tree within the $i$ th plot.
6. To recalculate $l_{i j}$

$l_{i j}=\left\{k \mid \min \left\{\left|1.3+\cdot a_{k} \cdot\left(1-\mathrm{e}^{-b \cdot d_{i j}}\right)^{c}-h_{i j}\right|, k=1,2\right.\right.$, $\ldots, m\}\}$

$t_{1}=t_{1}+1$

8. To calculate $l_{i}$ and to recalculate $l_{i j}$

$l_{i}=\left\{k \mid \min \left\{\sum_{j=1}^{n_{i}}\left(1.3+\cdot a_{k} \cdot\left(1-\mathrm{e}^{-b \cdot d_{i j}}\right)^{c}-h_{i j}\right)^{2}\right.\right.$

$k=1,2, \ldots, m\}\}$

$l_{i j}=l_{i}$

$t_{2}=t_{2}+1$

where, $l_{i}$ is tree height class of $i$ th plot. $n_{i}$ is number of samples within $i$ th plot.
7. If $l_{i j}^{\left(t_{1}\right)} \neq l_{i j}^{\left(t_{1}-1\right)}$, return to step (4), else go to next step. 
Fig. 1 The region from which the data were collected

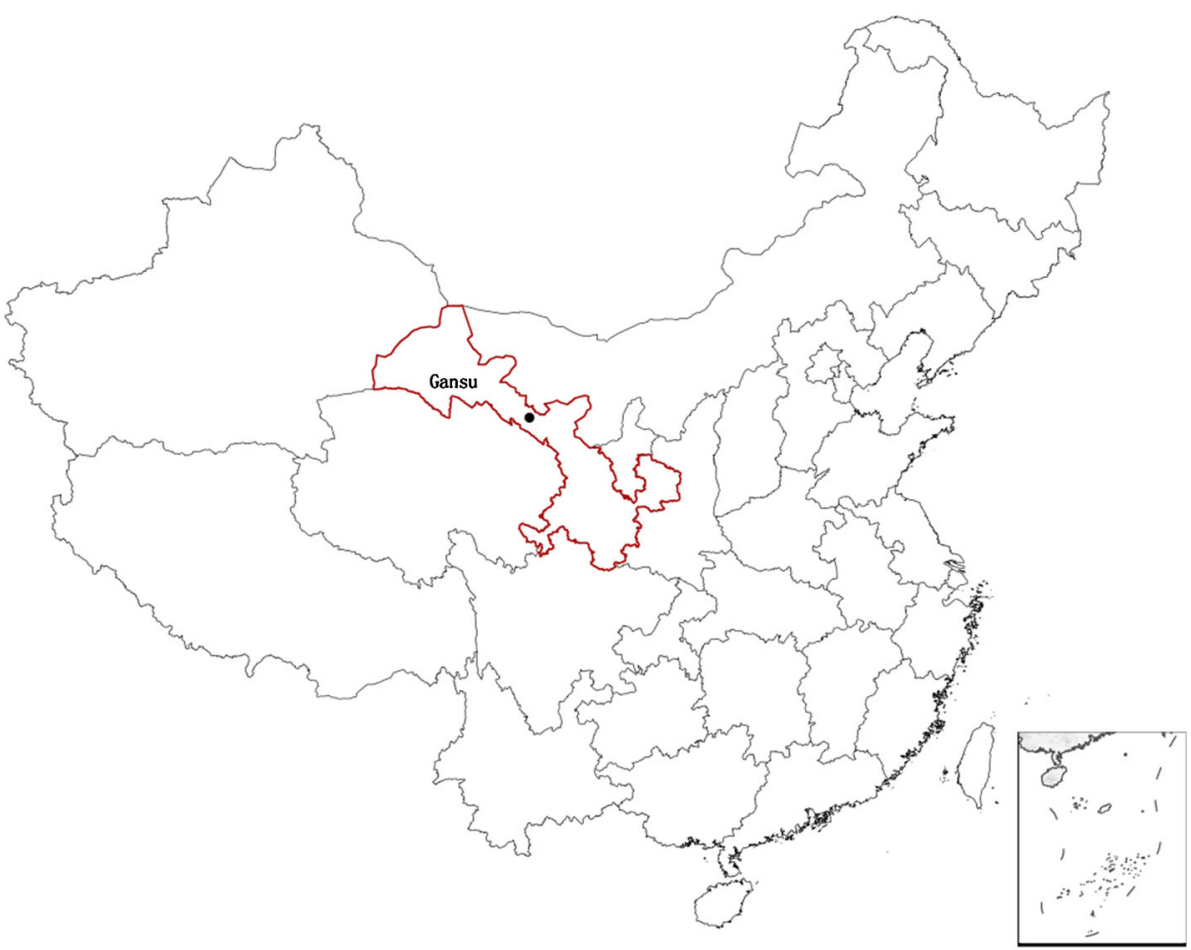

9. If $l_{i}^{\left(t_{2}\right)} \neq l_{i}^{\left(t_{2}-1\right)}$, return to step (8), else end.

The classified factors method

The classified factors method was put forward based on the classified height method. The Chapman-Richard equation Eq. (1) was used as fundamental function as well.

The algorithm of the classified factors method follows:

1. To study the correlation between factor and height The relationship plots (height class versus factor) are drawn and linear equations are built to demonstrate the correlation between height class and factor.

2. To build height-diameter model for each factor According to the correlations, each factor is divided into several classes (with aspect as an example to describe), then the model data set and validation data set are divided into several levels in terms of factor classes:

$l_{i}=\operatorname{aspect}_{i}$

$l_{i j}=l_{i}$

where, aspect $_{i}$ is the aspect class for $i$ th plot. aspect ${ }_{i}=1$, $2, \ldots m_{\text {aspect }} \cdot m_{\text {aspect }}$ is the number of aspect classes.

3 To execute step (4) and (5) in "The classified factors method" section, where $m=m_{\text {aspect }}$.

4. To calculate $\left(f_{\text {aspect }}\right)_{k}$ of each class of aspect

$f_{\text {aspect }}^{k}=f_{\text {aspect }}^{\max } \cdot \frac{a_{\text {aspect }}^{k}}{a_{\text {aspect }}^{\text {max }}}, \quad f_{\text {aspect }}^{\text {max }}=1$, where, $f_{\text {aspect }}^{k}$ is the value of influence of $k$ th aspect class on height growth. $f_{\text {aspect }}^{\max }$ is the maximum value of influence of aspect classes on height growth. $a_{\text {aspect }}^{k}$ is parameter $a$ in Eq. (2). $a_{\mathrm{aspect}}^{\max }$ is the maximum value of $a_{\text {aspect }}^{k}$.

5. To calculate $f_{\text {aspect }}$ for each tree sample

$\left(f_{\text {aspect }}\right)_{i j}=f_{\text {aspect }}^{l_{i j}}$

where, $\left(f_{\text {aspect }}\right)_{i j}$ is the value of influence of aspect on $j$ th sample tree within the $i$ th plot.

6. To calculate $f_{\mathrm{t}}$ for each tree sample

$\left(f_{t}\right)_{i j}=\left(f_{\text {aspect }}\right)_{i j} \cdot\left(f_{\text {altitude }}\right)_{i j} \cdot\left(f_{\text {position }}\right)_{i j}$

where, $f_{\mathrm{t}}$ is the value of integrated influence of 3 topographic factors. $\left(f_{\text {altitude }}\right)_{i j}$ and $\left(f_{\text {position }}\right)_{i j}$ are respectively the value of influence of altitude and slope position on $j$ th sample tree within the $i$ th plot. The calculations of $\left(f_{\text {altitude }}\right)_{i j}$ and $\left(f_{\text {position }}\right)_{i j}$ are the same as $\left(f_{\text {aspect }}\right)_{i j}$.

7. To fit Eq. (5) and estimate $a, b$ and $c$

$$
h_{i j}=1.3+\left(f_{\mathrm{t}}\right)_{i j} \cdot a \cdot\left(1-\mathrm{e}^{-b \cdot d_{i j}}\right)^{c}+\varepsilon_{i j}
$$

Model evaluation

Determination coefficient $\left(R^{2}\right)$ and root mean square error (RMSE) were used to evaluate goodness of fit; mean error (ME), mean absolute error (MAE) and mean relative error 
(MRE) were used to evaluate prediction accuracy of models. They are defined as follows:

$R^{2}=1-\frac{\sum_{\mathrm{i}=1}^{\mathrm{n}}\left(y_{i}-\hat{y}_{i}\right)^{2}}{\sum_{\mathrm{i}=1}^{\mathrm{n}}\left(y_{i}-\bar{y}\right)^{2}}$

$\mathrm{RMSE}=\sqrt{\frac{\sum_{\mathrm{i}=1}^{\mathrm{n}}\left(y_{i}-\hat{y}_{i}\right)^{2}}{n-p}}$

where, $n$ is the number of fitting samples; $p$ is number of height classes; $y_{i}$ and $\hat{y}_{i}$ are respectively measured value and predicted value of $i$ th fitting sample; $\bar{y}_{i}$ is mean measured value of fitting samples.

$\mathrm{MAE}=\frac{1}{m} \sum_{\mathrm{j}=1}^{\mathrm{m}}\left|y_{j}-\hat{y}_{j}\right|$

$\operatorname{MRE}=\frac{1}{m} \sum_{\mathrm{j}=1}^{\mathrm{m}} \frac{\left|y_{j}-\hat{y}_{j}\right|}{y_{j}}$

where, $m$ is number of validation samples; $y_{j}$ and $\hat{y}_{j}$ are respectively measured value and predicted value of $j$ th validation sample.

\section{Results}

Height-diameter relationship modeling using the classified height method

Models (1) and (2) were built using the classical ChapmanRichard model and classified height method, respectively. The formulas of Models (1) and (2) could be expressed by Eqs. (1) and (2), respectively. In Model (2), tree samples were divided into 7 classes in terms of height; in other words, modeling samples and validation samples were divided into 7 subsamples.

Table 2 displays estimated parameters, fit characteristics ( $R^{2}$ and RMSE) and prediction statistics (MAE and MRE) for Models (1) and (2). From Model (1) to Model (2), $R^{2}$ increased from 0.820 to 0.927 , RMSE decreased from 2.392 to 1.548 , MAE decreased from 1.534 to 1.152 , and MRE decreased from 0.211 to 0.159 . The increased values of $R^{2}$ and the decreased values of RMSE improved fit statistics, while the decreased values of MAE and MRE improved prediction accuracy. In this study, fit statistics and prediction accuracy both improved significantly from Model (1) to Model (2).

Figure 2 displays 7 curves generated by Model (2). Seven curves were mapped onto 7 tree height classes. The expression $(a+1.3)$ stands for maximum tree height growth. From class 1 to class 7, $a$ increased from 17.03 to 30.69. In other words, the maximum tree height growth increased from 18.33 to $31.69 \mathrm{~m}$. Across 7 classes, MAE was distributed between 0.968 and 2.429 (class 6 had the largest MAE); and MRE was distributed between 0.120 and 0.227 (class 1 had the largest MRE). Class 1 and class 6 performed worse than other classes in prediction accuracy. Class 3 and class 5 produced the most accurate predictions.

The parameters $a, b, c$ of the Chapman-Richard equation stand for maximum growth (asymptote of curve), growth rate (slope of curve) and change of growth rate (concavity of curve) respectively. However, the classical Chapman-Richard equation can only explain the average maximum height growth of all kinds of sites. Taking into account the significant influence of site on height-diameter curve, the maximum height growth of each site must be explained using the classified height model.

Relationship between height class and topographic factors

It is essential that a link be established between height class and topographic factors. Figure 3 a shows that the value of height class decreases as the aspect changes from the north slope to the south slope (the azimuth changes from $0^{\circ}$ to $180^{\circ}$ ); on the other hand it increases as the aspect changes from the south slope to the north slope (the azimuth changes from $180^{\circ}$ to $360^{\circ}$ ). In the northern hemisphere, the north slope is ubac, the south slope is the sunny slope, and the northeastern/northwestern slope, eastern/western slope and southeastern/southwestern slope are interims. In other words, from the ubac to the sunny slope, the value of the height class increases.

Figure $3 \mathrm{~b}$ specifically shows the relationship between height class and altitude. The values of the height class decreases significantly as the altitude increases where the altitude is higher than 3000 meters; however, there is no apparent correlation where the altitude is lower than 3000 meters.

Figure $3 \mathrm{c}$ shows that the value of the height class decreases as the slope position rises.

Models (3)-(5) was created to express the relationship between height and aspect, and altitude and slope position respectively using the classified topographic factors method. The formulas of Models (3)-(5) could be expressed by Eq. (2). Table 3 displays estimated parameters, fit characteristics and prediction accuracy of Model (3)-(5). Of these 3 models, Model (4) had the highest $R^{2}(0.909)$ and the lowest RMSE (1.730), MAE (1.278) and MRE (0.196). In other words, Model (4) performed best with regards to fitting and prediction. All 3 models performed better than Model (1) but worse than Model (2) on both 
Table 2 Parameters $(a, b$ and $c)$ and fit characteristics ( $R^{2}$ and RMSE) for Model (1) and (2)

\begin{tabular}{|c|c|c|c|c|c|c|c|c|c|c|c|c|c|}
\hline \multirow[t]{2}{*}{ Models } & \multirow[t]{2}{*}{ Classes } & \multicolumn{2}{|c|}{ Number of samples } & \multicolumn{2}{|l|}{$a$} & \multicolumn{2}{|l|}{$b$} & \multicolumn{2}{|l|}{$c$} & \multicolumn{2}{|c|}{$\begin{array}{l}\text { Fit } \\
\text { characteristics }\end{array}$} & \multicolumn{2}{|c|}{$\begin{array}{l}\text { Prediction } \\
\text { accuracy }\end{array}$} \\
\hline & & Fitting & Validation & Estimate & SD & Estimate & SD & Estimate & SD & $R^{2}$ & RMSE & MAE & MRE \\
\hline (1) Classical Richard & - & 574 & 385 & 22.39 & 0.637 & 0.073 & 0.005 & 1.758 & 0.085 & 0.820 & 2.392 & 1.534 & 0.211 \\
\hline \multirow{8}{*}{$\begin{array}{l}\text { (2) Richard with } \\
\text { height } \\
\text { classification }\end{array}$} & 1 & 46 & 31 & 17.03 & 0.862 & 0.062 & 0.004 & 1.591 & 0.066 & 0.927 & 1.548 & 1.119 & 0.227 \\
\hline & 2 & 83 & 56 & 20.62 & 0.677 & & & & & & & 1.087 & 0.169 \\
\hline & 3 & 115 & 77 & 22.37 & 0.786 & & & & & & & 0.968 & 0.136 \\
\hline & 4 & 128 & 86 & 23.78 & 0.751 & & & & & & & 1.257 & 0.139 \\
\hline & 5 & 171 & 115 & 25.70 & 0.885 & & & & & & & 1.129 & 0.120 \\
\hline & 6 & 7 & 4 & 27.84 & 0.924 & & & & & & & 2.439 & 0.156 \\
\hline & 7 & 24 & 16 & 30.69 & 0.978 & & & & & & & 1.574 & 0.188 \\
\hline & Total & 574 & 385 & & & & & & & & & 1.152 & 0.159 \\
\hline
\end{tabular}

$S D$ standard deviation

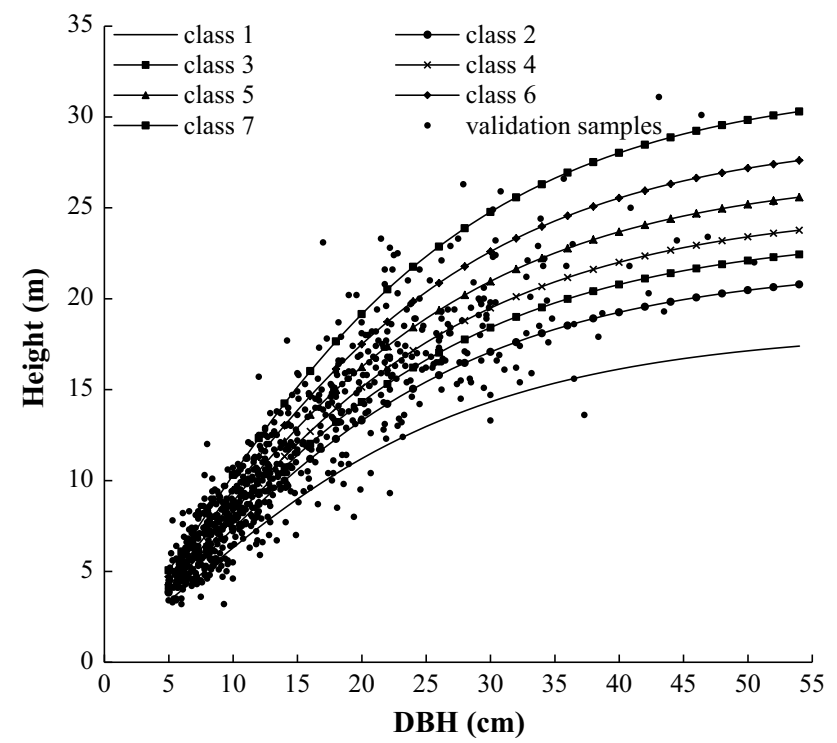

Fig. 2 Validation samples and prediction curves of Model (2)

fitting and prediction. This can be explained by the fact that Model (2) took into account more factors, while Model (3)/ (4)/(5) took into account just one factor.

Table 4 shows the classification of topographic factors. Figure 3d-f shows the curves of Model (3)-(5). Model (3) contains 5 classes in respect of 5 kinds of aspect. The values of parameter (a) range from 19.97 to 24.35 across classes, with a range of 4.38 . The largest interval between adjacent classes is the interval between class 3 and class 4 , with a value of 1.58; with the smallest interval being between class 2 and class 3, with a value of 0.46 . Model (4) contains 4 classes in respect of 4 levels of altitude. The values of parameter (a) range from 19.64 to 24.73 across classes, with a range of 5.09. The largest interval between adjacent classes is the interval between class 3 and class 4 , with a value of 2.73 ; with the smallest interval being between class 1 and class 2, with a value of 0.73 . Model (5) contains 5 classes in respect of 5 levels of slope position; these which are ridge, top slope, middle slope, bottom slope and valley. The values of parameter $a$ range from 20.40 to 24.70 across classes, with a range of 4.30 . The largest interval between adjacent classes is the interval between class 3 and class 4 , with a value of 1.39; with the smallest interval being between class 1 and class 2 , with a value of 0.76 .

Parameter $a$ significantly increased across classes in all three models. In other words, aspect, altitude and slope position had an obvious influence on tree height growth.

Height-diameter relationship modeling using the classified factors method

The $f_{\text {aspect }}, f_{\text {altitude }}$ and $f_{\text {position }}$ of each factor in each class were calculated using Eq. (3) (Table 4). The $f_{\mathrm{t}}$ of each tree sample was calculated using Eq. (4). Model (6) was produced, whose formula could be expressed by Eq. (5). Table 5 displays estimated parameters, fit characteristics and prediction accuracy of Model (6). The value of $R^{2}$ of Model (6) was 0.914, which was lower than that of Model (2); the value of RMSE of Model (6) was 1.702, which was higher than that of Model (2). In this instance, the fitting performance of Model (6) was worse than Model (2). The value of MAE and MRE were 1.137 and 0.109 respectively; both lower than Model (2). In other words, the prediction accuracy of Model (6) was higher than Model (2). In addition, Model (6) performed better than Model (1) both in fitting and prediction.

Mean bias and its standard deviation were calculated for Models (1), (2) and (6) (Table 6). These values were smaller for Model (6) than for Model (2) and (1). As a further analysis, residual plots (bias versus predicted height) were drawn for models using the validation data set (Fig. 4). These 
(a)
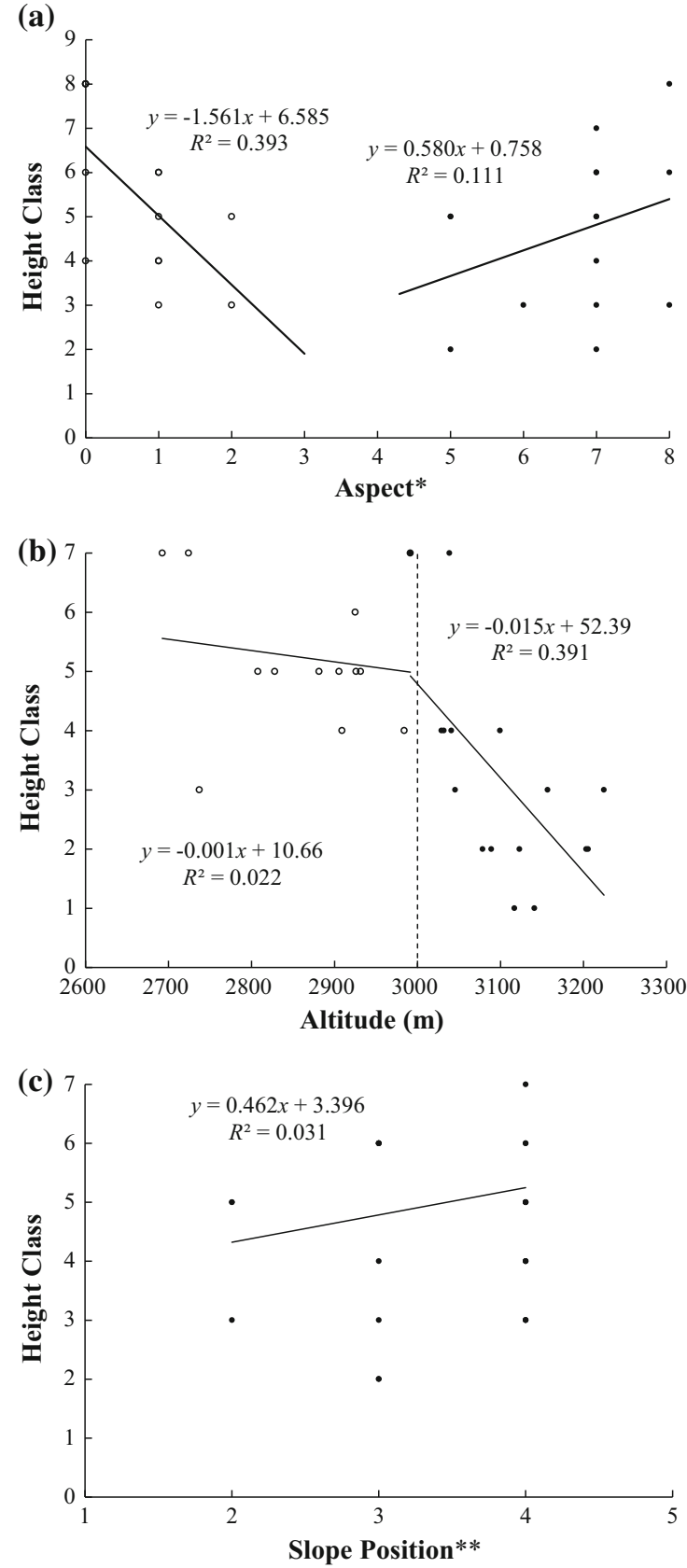

Fig. 3 The relationships between height classes and topographic factors and the curves of Model (3)-(5). Asterisk aspect was divided into 9 aspects according to azimuth $(\theta)$ : $0-\theta \in\left[0-22.5^{\circ}\right), \mathrm{N} ; 1-$ $\theta \in\left[22.5-67.5^{\circ}\right), \mathrm{NE}, 2-\theta \in\left[67.5-112.5^{\circ}\right), \mathrm{E}, 3-\theta \in\left[112.5-157.5^{\circ}\right)$,

plots demonstrate that Model (6) was the strongest performer in predicting tree height, followed Model (2).

Overall, Model (2) performed best in fitting, while Model (6) was the best predictor. By contrast, Model (1) performed worst in both fitting and prediction. The fitting of Model (2) took into consideration almost all influencing factors on height growth and divided them into 7 classes; however, just 3 factors were taken into
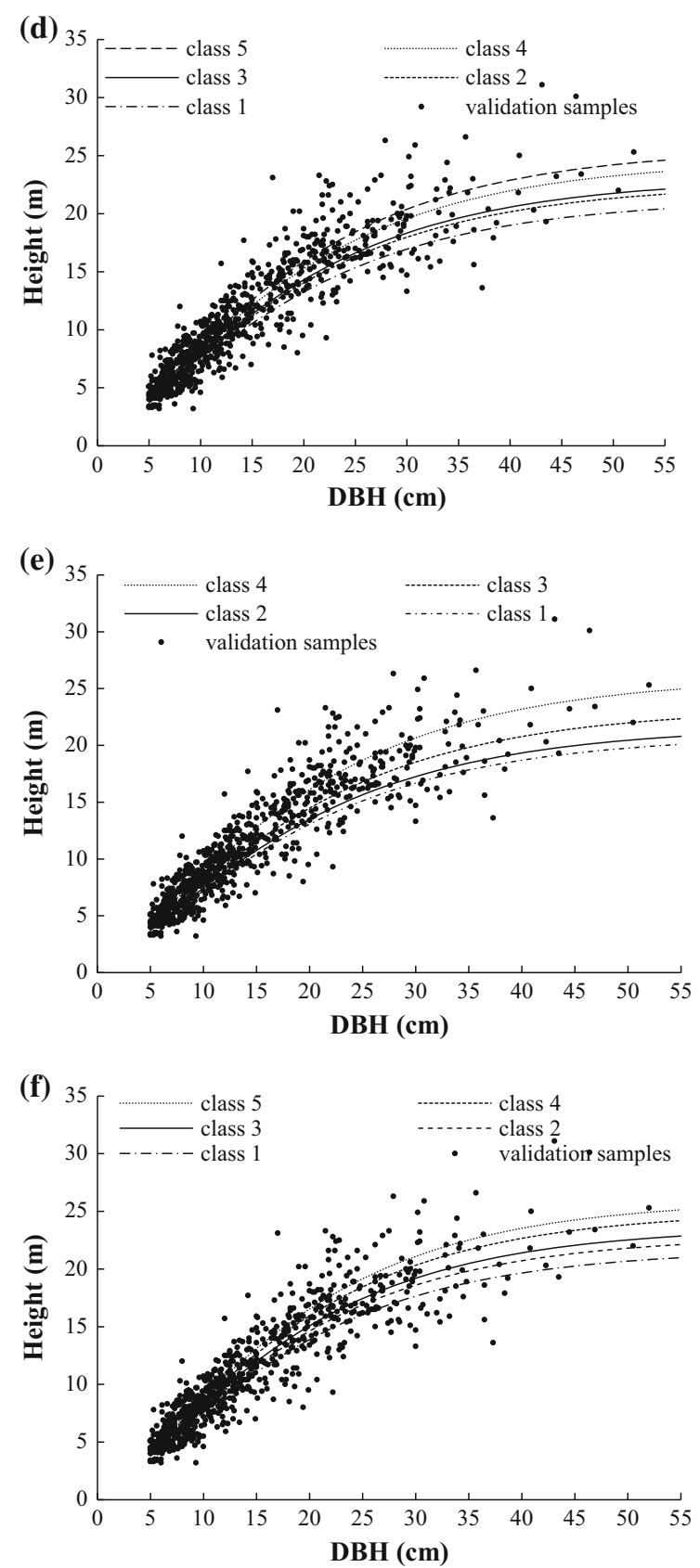

SE; $4-\theta \in\left[157.5-202.5^{\circ}\right), \quad S ; \quad 5-\theta \in\left[202.5-247.5^{\circ}\right), \quad S W ; 6-\theta \in$ $\left[247.5-292.5^{\circ}\right), \mathrm{W} ; 7-\theta \in\left[292.5-337.5^{\circ}\right), \mathrm{NW} ; 8-\theta \in\left[337.5-360^{\circ}\right)$, N. Double asterisk Slope position was divided into 5 aspects: 1 ridge, 2 top slope, 3 middle slope, 4 bottom slope, 5 valley

consideration in the fitting of Model (6). Hence Model (2) was able to describe the relationship between height and diameter for the model data set more accurately. Having said this, most factors considered in Model (2) could not be measured while by contrast, 3 factors taken into consideration in Model (6) were measurable. Therefore, Model (6) was superior at prediction (Fig. 5). 
Table 3 Parameters ( $a, b$ and $c)$ and fit characteristics ( $R^{2}$ and RMSE) for Models (3)-(5)

\begin{tabular}{|c|c|c|c|c|c|c|c|c|c|c|c|c|c|}
\hline \multirow[t]{2}{*}{ Models } & \multirow[t]{2}{*}{ Classes } & \multicolumn{2}{|c|}{ Number of samples } & \multicolumn{2}{|l|}{$a$} & \multicolumn{2}{|l|}{$b$} & \multicolumn{2}{|l|}{$c$} & \multicolumn{2}{|c|}{$\begin{array}{l}\text { Fit } \\
\text { characteristics }\end{array}$} & \multicolumn{2}{|c|}{$\begin{array}{l}\text { Prediction } \\
\text { accuracy }\end{array}$} \\
\hline & & Fitting & Validation & Estimate & $\mathrm{SD}$ & Estimate & SD & Estimate & $\mathrm{SD}$ & $R^{2}$ & RMSE & MAE & MRE \\
\hline \multirow{6}{*}{$\begin{array}{l}\text { (3) Richard with } \\
\text { aspect } \\
\text { classification }\end{array}$} & 1 & 0 & 0 & $19.97^{\mathrm{a}}$ & - & \multirow[t]{6}{*}{0.0668} & \multirow[t]{6}{*}{0.005} & \multirow[t]{6}{*}{1.6820} & \multirow[t]{6}{*}{0.080} & \multirow[t]{6}{*}{0.892} & \multirow[t]{6}{*}{1.882} & - & - \\
\hline & 2 & 19 & 11 & 21.28 & 0.782 & & & & & & & 1.806 & 0.257 \\
\hline & 3 & 58 & 39 & 21.74 & 0.793 & & & & & & & 1.196 & 0.193 \\
\hline & 4 & 361 & 244 & 23.32 & 0.782 & & & & & & & 1.292 & 0.227 \\
\hline & 5 & 136 & 91 & 24.35 & 0.849 & & & & & & & 1.582 & 0.161 \\
\hline & Total & 574 & 385 & & & & & & & & & 1.367 & 0.209 \\
\hline \multirow{5}{*}{$\begin{array}{l}\text { (4) Richard with } \\
\text { altitude } \\
\text { classification }\end{array}$} & 1 & 433 & 259 & 19.64 & 0.689 & \multirow[t]{5}{*}{0.0661} & \multirow[t]{5}{*}{0.004} & \multirow[t]{5}{*}{1.6536} & \multirow[t]{5}{*}{0.072} & \multirow[t]{5}{*}{0.909} & \multirow[t]{5}{*}{1.730} & 1.381 & 0.143 \\
\hline & 2 & 288 & 172 & 20.37 & 0.687 & & & & & & & 1.059 & 0.153 \\
\hline & 3 & 185 & 110 & 22.00 & 0.688 & & & & & & & 1.236 & 0.403 \\
\hline & 4 & 53 & 33 & 24.73 & 0.734 & & & & & & & 1.302 & 0.143 \\
\hline & Total & 574 & 385 & & & & & & & & & 1.278 & 0.196 \\
\hline \multirow{6}{*}{$\begin{array}{l}\text { (5) Richard with } \\
\text { slope position } \\
\text { classification }\end{array}$} & 1 & 0 & 0 & $20.40^{\mathrm{a}}$ & - & \multirow[t]{6}{*}{0.0708} & \multirow[t]{6}{*}{0.005} & \multirow[t]{6}{*}{1.7364} & \multirow[t]{6}{*}{0.083} & \multirow[t]{6}{*}{0.892} & \multirow[t]{6}{*}{1.889} & - & - \\
\hline & 2 & 77 & 53 & 21.58 & 0.751 & & & & & & & 1.206 & 0.140 \\
\hline & 3 & 180 & 119 & 22.34 & 0.646 & & & & & & & 1.731 & 0.356 \\
\hline & 4 & 317 & 213 & 23.73 & 0.758 & & & & & & & 1.233 & 0.153 \\
\hline & 5 & 0 & 0 & $24.70^{\mathrm{a}}$ & - & & & & & & & - & - \\
\hline & Total & 574 & 385 & & & & & & & & & 1.385 & 0.215 \\
\hline
\end{tabular}

a The values of $a$ in the classes of 0 sample tree were calculated by linear extrapolation approach

Table 4 The classification of 3 topographic factors (aspect, altitude and slope position)

\begin{tabular}{|c|c|c|c|c|c|c|}
\hline \multirow[t]{2}{*}{ Factors } & & \multicolumn{5}{|l|}{ Classes } \\
\hline & & 1 & 2 & 3 & 4 & 5 \\
\hline \multirow[t]{3}{*}{ Aspect } & Range & Southern & Southeastern/southwestern & Eastern/western & Northeastern/northwestern & Northern \\
\hline & $a+1.3$ & 21.27 & 22.58 & 23.04 & 24.62 & 25.65 \\
\hline & $f$ & 0.829 & 0.880 & 0.898 & 0.960 & 1 \\
\hline \multirow[t]{3}{*}{ Altitude } & Range & $\geq 3200 \mathrm{~m}$ & [3100 m, $3200 \mathrm{~m})$ & [3000 m, $3100 \mathrm{~m})$ & $<3000 \mathrm{~m}$ & \\
\hline & $a+1.3$ & 20.94 & 21.67 & 23.30 & 26.03 & \\
\hline & $f$ & 0.805 & 0.833 & 0.895 & 1.000 & \\
\hline \multirow[t]{3}{*}{ Slope position } & Range & Ridge & Top slope & Middle slope & Bottom slope & Valley \\
\hline & $a+1.3$ & 21.70 & 22.88 & 23.64 & 25.03 & 26.00 \\
\hline & $f$ & 0.834 & 0.880 & 0.909 & 0.963 & 1 \\
\hline
\end{tabular}

Table 5 Parameters, fit characteristics and prediction accuracy for Model (6)

\begin{tabular}{|c|c|c|c|c|c|c|c|c|c|c|}
\hline \multirow[t]{2}{*}{ Model } & \multicolumn{2}{|l|}{$a$} & \multicolumn{2}{|l|}{$b$} & \multicolumn{2}{|l|}{$c$} & \multicolumn{2}{|c|}{$\begin{array}{l}\text { Fit } \\
\text { characteristics }\end{array}$} & \multicolumn{2}{|c|}{$\begin{array}{l}\text { Prediction } \\
\text { accuracy }\end{array}$} \\
\hline & Estimate & SD & Estimate & SD & Estimate & SD & $R^{2}$ & RMSE & MAE & MRE \\
\hline (6) Richard with topographic factors classification & 30.52 & 0.781 & 0.0639 & 0.004 & 1.6283 & 0.075 & 0.914 & 1.702 & 1.137 & 0.109 \\
\hline
\end{tabular}

\section{Discussion and conclusion}

Moisture, nutrient, light and temperature play crucial roles for the growth of trees (Duan et al. 2011; Ma et al. 2014). This fact is embodied in the closed relationship between tree height and topographic factors (altitude, slope, slope position and aspect). The aspect is a topographic factor in the horizontal direction. There existed distinct differences in tree height among trees which grow up in different aspects, because aspect significantly affects intensity and 
Table 6 Description of prediction bias of Models (1), (2) and (6)

\begin{tabular}{lll}
\hline Methods & Prediction bias & \\
\cline { 2 - 3 } & Mean bias & SD \\
\hline (1) Classical Chapman-Richard & 0.036 & 3.815 \\
(2) Richard with height classification & 0.021 & 2.237 \\
(6) Richard with topographic factors classification & 0.019 & 2.021 \\
\hline
\end{tabular}

(a)
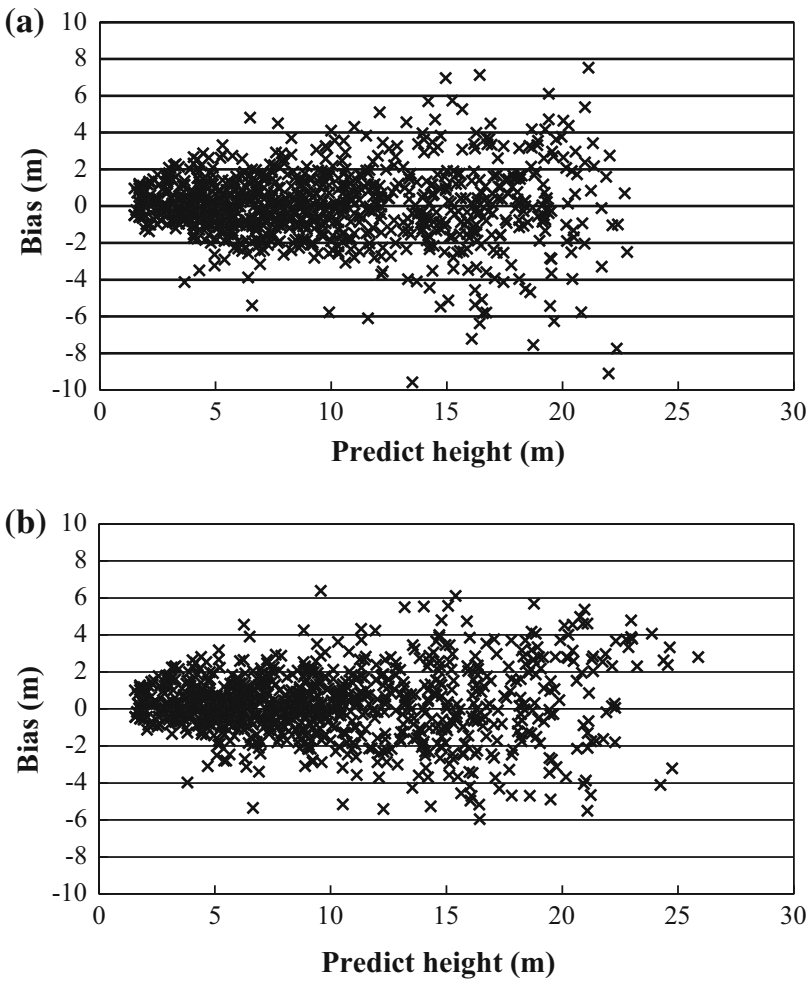

(c)

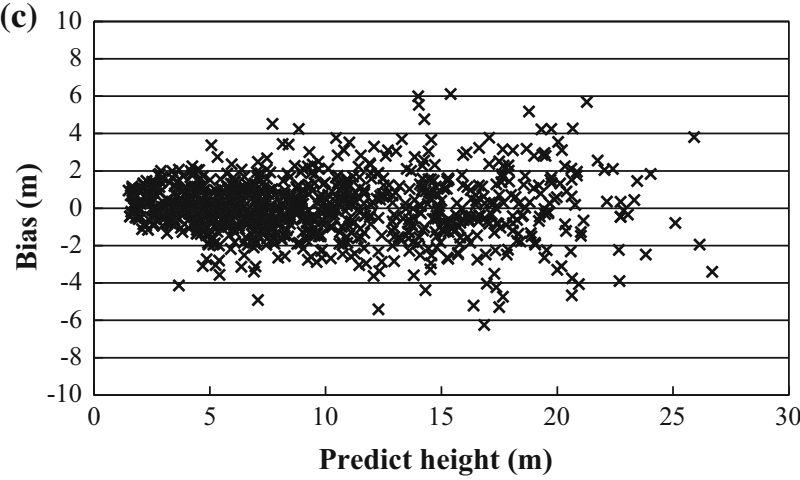

Fig. 4 Bias (= observed - predicted) in predicting total heights of Model (1) (a), Model (2) (b) and Model (6) (c)

duration of solar radiation that vegetation receives. The maximum tree height of $P$. crassifolia decreases gradually, as aspect changes from sunny slope into semisunny slope, and changes from semi-sunny slope into semi-cloudy slope. Altitude, slope and slope position are three topographic factors in the vertical direction. Altitude

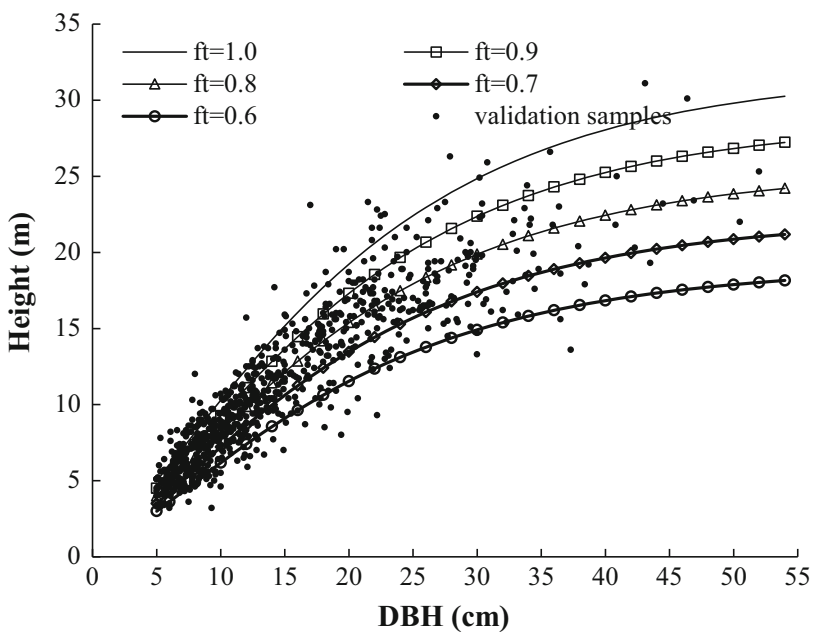

Fig. 5 Validation samples and prediction curves of Model (6)

influences temperature. With the rising of altitude, atmospheric and soil temperature decreases, in consequence, the growth of trees is restrained and the maximum tree height decreases. Slope position and slope are associated with moisture and nutrient. With the increasing of slope and the rising of slope position, retaining capacity of soil moisture and nutrient reduces (Song et al. 2012; Xu et al. 2011).

In mountainous forest area, the growth of a vegetation community is generally constrained by several topographic factors (Wang et al. 2013). In this study, tree height of $P$. crassifolia forest was impressible to the change of topography. Height-diameter models which take into account topographic factors have improved prediction accuracy than classical model.

The height-diameter relationship model using the classified factors method is biologically feasible and improves prediction accuracy. In terms of fitting, however, the model which uses the classified factors method performs worse than the classified height method on account of considering fewer factors.

The classified factors method is improved when based on the classified height method, and when factor classes are correlated with height classes. This method can accurately predict tree height in terms of DBH and topographic factors, even though no sample trees are measured for height in the stand or plot. 


\section{References}

Calama R, Montero G (2004) Interregional nonlinear height-diameter model with random coefficients for stone pine in Spain. Can $\mathbf{J}$ For Res 34(1):150-163

Chapman DG (1961) Statistical problems in dynamics of exploited fisheries populations. In: Neyman $\mathbf{J}$ (ed) Proceedings of 4th Berkeley symposium on mathematical statistics and probability, vol 4. Berkeley, pp 153-168

Curtis RO (1967) Height-diameter and height-diameter-age equations for second growth Douglas-fir. For Sci 13(4):365-375

Duan H, Yan C, Tsunekawa A, Song X, Li S, Xie J (2011) Assessing vegetation dynamics in the Three-North Shelter Forest region of China using AVHRR NDVI data. Environ Earth Sci 64(4):1011-1020

Esteban GG, Ulises DA, Fernando CD, Felipe CC (2014) A comparison of model forms for the development of heightdiameter relationships in even-aged stands. For Sci 60(3):560-568

Fang ZX, Bailey RL (1998) Height-diameter models for tropical forests on Hainan Island in southern China. For Ecol Manage 110(1-3):315-327

Fekedulengn D, Siurtain MPM, Colbert JJ (1999) Parameter estimation of nonlinear growth models in forestry. Silv Fenn 33(4):327-336

Fulton MR (1999) Patterns in height-diameter relationship for selected tree species and sites in eastern Texas. Can J For Res 29(9): 1445-1448

Huang SM, Titus SJ, Wiens DP (1992) Comparison of nonlinear height-diameter functions for major Alberta tree species. Can J For Res 22(9):1297-1304

Huang SM, Price D, Titus SJ (2000) Development of ecoregion-based height-diameter models for white spruce in boreal forests. For Ecol Manage 129(1-3):125-141

Jayaraman K, Zakrzewski WT (2001) Practical approaches to calibrating height-diameter relationships for natural sugar maple stands in Ontario. For Ecol Manage 148(1-3):169-177

Larsen, Hann DW (1987) Height-diameter equations for seventeen tree species in southwest Oregon, For Res Lab Res Pap 4. Oreg State Univ, Corvallis

Lei XD, Peng CH, Wang HY, Zhou XL (2009) Individual heightdiameter models for young black spruce (Picea mariana) and jack pine (Pinus banksiana) plantations in New Brunswick, Canada. For Chron 85(1):43-56

Li HK, Fa L (2011) Height-diameter model for major tree species in China using the classified height method. Sci Silvae Sin 47(10):83-90

Li HK, Zhao PX (2013) Improving the accuracy of tree-level aboveground biomass equations with height classification at a large regional scale. For Ecol Manage 289:153-163

Ma Y, Van Dam RL, Jayawickreme DH (2014) Soil moisture variability in a temperate deciduous forest: insights from electrical resistivity and throughfall data. Environ Earth Sci 72(5):1367-1381

Mehtätalo L (2004) A longitudinal height-diameter model for Norway spruce in Finland. Can J For Res 34(1):131-140

Newton RF, Amponsah (2007) Comparative evaluation of five height-diameter models developed for black spruce and jack pine stand-types in terms of goodness-of-fit, lack-of-fit and predictive ability. For Ecol Manage 247(1-3):149-166
Peng C, Zhang L, Liu J (2001) Developing and validating nonlinear height-diameter models for major tree species of Ontario's boreal forests. North J Appl For 18:87-94

Ratkowsky DA, Reedy TJ (1986) Choosing near-linear parameters in the four-parameter logistic model for radioligand and related assays. Biometrics 42(3):575-582

Richards FJ (1959) A flexible growth function for empirical use. J Exp Biol 10(2):290-301

Robinson AP, Wykoff WR (2004) Imputing missing height measures using a mixed-effects modeling strategy. Can J For Res 34(12):2492-2500

Schnute J (1981) A versatile growth model with statistically stable parameters. Can J Fish Aquat Sci 38(9):1128-1140

Sharma M, Parton J (2007) Height-diameter equations for boreal tree species in Ontario using a mixed-effects modeling approach. For Ecol Manage 249(3):187-198

Sharma M, Zhang SY (2004) Height-diameter models using stand characteristics for Pinus banksiana and Picea mariana. Scand J For Res 19(5):442-451

Song X, Yan C, Xie J, Li S (2012) Assessment of changes in the area of the water conservation forest in the Qilian Mountains of China's Gansu province, and the effects on water conservation. Environ Earth Sci 66(8):2441-2448

Stage AR (1963) A mathematical approach to polymorphic site index curves for grand fir. For Sci 9:167-180

Temesgen H, Monleon VJ, Hann DW (2008) Analysis and comparison of nonlinear tree height prediction strategies for Douglas-fir forests. Can J For Res 38(3):553-565

Temesgen H, Zhang CH, Zhao XH (2014) Modeling tree heightdiameter relationships in multi-species and multi-layered forests: a large observational study from Northeast China. For Ecol Manage 316(SI):78-89

Wang CH, Hann DW (1988) Height-diameter equations for sixteen tree species in the central western Willamette valley of Oregon, For Res Lab Res Pap 51. Oreg State Univ, Corvallis

Wang Y, Hou X, Wang M, Wu L, Ying L, Feng Y (2013) Topographic controls on vegetation index in a hilly landscape: a case study in the Jiaodong Peninsula, eastern China. Environ Earth Sci 70(2):625-634

Wykoff WR, Crookston NL, Stage AR (1982) User's guide to the stand prognosis model. United States Department of Agriculture, Forest Service, Intermountain Forest and Range Experiment Station Ogden UT84401, General Technical Report INT-122

$\mathrm{Xu} \mathrm{W,} \mathrm{Chen} \mathrm{X,} \mathrm{Luo} \mathrm{G,} \mathrm{Zhang} \mathrm{Q,} \mathrm{Lin} \mathrm{Q} \mathrm{(2011)} \mathrm{Soil} \mathrm{properties} \mathrm{at} \mathrm{the}$ tree limits of the coniferous forest in response to varying environmental conditions in the Tianshan Mountains, Northwest China. Environ Earth Sci 63(4):741-750

Yang RC, Kozak A, Smith JHG (1978) The potential of Weibull-type functions as a flexible growth curve. Can J For Res 8:424-431

Zeide B (1989) Accuracy of equations describing diameter growth. Can J For Res 19(10):1283-1286

Zhang LJ (1997) Cross-validation of non-linear growth functions for modeling tree height-diameter relationships. Ann Bot 79(3):251-257

Zhang LJ, Peng CH, Huang SM, Zhou XL (2002) Development and evaluation of ecoregion-based jack pine height-diameter models for Ontario. For Chron 78(4):530-538 